\title{
Cultura, práticas e saberes no trabalho desenvolvido na Pastoral da Saúde e a relação com a Política Pública de Saúde
}

\author{
Cultura, prácticas y conocimientos en el trabajo del Ministerio de Salud y \\ la relación con la política de salud pública
}

\author{
Culture, practices and knowledge in the work developed in the Pastoral of \\ Health and the relation with the Public Health Policy
}

\author{
Angela Quintanilha Gomes ${ }^{1}$ \\ Fernanda Cristina Foss de Zorzi ${ }^{2}$
}

\begin{abstract}
Resumo
Considerando a relevância da política pública de saúde vigente no país e também a necessidade de inclusão e acesso a todas as pessoas, visualiza-se a integração de ações de saúde, como práticas alternativas, que visem a qualidade de vida do cidadão. Este estudo foi elaborado com a finalidade de apresentar o trabalho realizado nas Pastorais da Saúde no município de São Borja/RS, evidenciando questões como cultura, práticas e saberes dos agentes da pastoral e o resultado deste na visão de quem utiliza (usuários) os produtos que ali são preparados. A Pastoral da Saúde possui sua organização e referência de trabalho em três dimensões (social, comunitária e sócio-política), inclusive na inter relação com a política pública de saúde vigente no país, atuando também na melhoria das condições de saúde da população que busca o serviço da Pastoral da Saúde. Para atingir a finalidade do trabalho traçamos como objetivo: analisar a cultura, práticas e saberes no trabalho desenvolvido nas Pastorais da Saúde do município na visão dos agentes da pastoral e dos usuários deste serviço. A metodologia utilizada foi quantitativa, com busca bibliográfica, coleta de dados (observação participante e questionário), análise e discussão dos resultados. Por fim, os objetivos do estudo foram alcançados, resultando no conhecimento da importância deste trabalho frente à coletividade e em conjunto à política pública de saúde e a política nacional de plantas fitoterápicas e medicinais.
\end{abstract}

Palavras chave: cultura, Pastoral da Saúde, políticas públicas.

\section{Resumen}

Teniendo en cuenta la importancia de la política pública de salud actual en el país y también la necesidad de la inclusión y el acceso a todas las personas, se ve la integración de las acciones de salud, tales como las prácticas

${ }^{1}$ Doutora em Ciência Política, Coordenadora do Programa de Pós Graduação em Políticas Públicas (Mestrado
Profissional) Universidade Federal do Pampa-Unipampa- São Borja- $\quad$ RS, email: angelagomes@unipampa.edu.br.

${ }^{2}$ Mestranda no Programa de Pós Graduação em Políticas Públicas (Mestrado Profissional)- Universidade Federal do Pampa- Unipampa- São Borja, RS; email: fcdezorzi@gmail.com. 
alternativas, orientadas a la calidad de vida de los ciudadanos. Este estudio fue elaborado con el fin de presentar el trabajo realizado en la Pastoral de la Salud en São Borja / RS, destacando temas como la cultura, las prácticas y los conocimientos de los agentes de pastoral y el resultado de esto en la vista de aquellos que utilizan (usuarios) Productos que no están preparados. El Ministerio de Salud tiene su organización y de referencia de trabajo en tres dimensiones (social, comunitario y socio-político), incluyendo la inter relación con la política pública de la salud actual en el país, actuando también en la mejora de las condiciones de salud de la población que busca . el servicio del Ministerio de Salud para lograr el propósito de la obra dibujamos los siguientes objetivos: analizar la cultura, las prácticas y conocimientos en el trabajo de la pastoral de salud del condado a la vista de los agentes pastorales y los usuarios de este servicio. La metodología utilizada fue cuantitativa con búsqueda en la literatura, la recogida de datos (cuestionario y participante de observación), el análisis y discusión de los resultados. Por último, se lograron los objetivos del estudio, lo que resulta en el conocimiento de la importancia de este trabajo a través de la comunidad y la política de salud pública juntos y la política nacional de plantas de hierbas y medicinales.

Palabras clave: cultura, políticas públicas, salud.

\begin{abstract}
Considering the relevance of the public health policy in force in the country and also the need for inclusion and access to all people, it is possible to visualize the integration of health actions, such as alternative practices, aimed at the quality of life of the citizen. This study was elaborated with the purpose of presenting the work carried out in the Pastorals of Health in the city of São Borja / RS, highlighting issues such as culture, practices and knowledge of pastoral agents and the result of this in the vision of who uses (products) the products Which are prepared there. The Ministry of Health has its organization and reference work in three dimensions (social, community and socio-political), including in the relationship with the public health policy in force in the country, also working to improve the health conditions of the population that seeks The service of the Pastoral of Health. In order to reach the purpose of the work we set out as objective: to analyze the culture, practices and knowledge in the work developed in the Pastoral Health of the city in the perspective of the pastoral agents and the users of this service. The methodology used was quantitative, with bibliographic search, data collection (participant observation and questionnaire), analysis and discussion of the results. Finally, the objectives of the study were achieved, resulting in the knowledge of the importance of this work vis-à-vis the community and in conjunction with public health policy and the national policy of herbal and medicinal plants.
\end{abstract}

Keywords: culture, Pastoral Health, public policies.

\title{
1 Do conceito de Pastoral da Saúde ao contexto local
}

Este estudo tem abordagem no trabalho desenvolvido nas Pastorais da Saúde no município de São Borja/RS, como forma de identificar, evidenciar e divulgar a presença da cultura, de práticas e de saberes desenvolvidos nestes locais. Para entendimento do que é pastoral comecemos com o texto abaixo:

Pastoral é um termo tradicionalmente utilizado pelo cristianismo, mais especificamente pela Igreja Católica. Não é um termo restrito à Igreja, mas no seu universo ele é utilizado frequentemente e tem um profundo significado. Para entendermos o que significa pastoral, é preciso falarmos do pastor, mais precisamente da atuação de um pastor, no sentido raso da palavra, e depois no sentido metafórico, quando se apropria dessa palavra para expressar outra realidade.( MARTINS, 2010, p. 547)

Mesmo com o direito fundamental à saúde amparado na Constituição Federal, ainda há dificuldade de acesso da população às ações que o sistema de saúde deve cumprir. $\mathrm{O}$ uso 
da medicina caseira se torna então uma prática constante e por vezes a única que se tem acesso. Em contribuição a estas práticas cada vez mais frequente do medicamento caseiro ou fitoterápico, no ano de 2006 surge uma política pública que normatiza o uso de plantas medicinais e fitoterápicas no sentido de auxiliar na melhor condição de saúde da população através de práticas alternativas como segue o texto abaixo:

\begin{abstract}
Nesse sentido, a Política Nacional de Plantas Medicinais e Fitoterápicos, aprovada por meio do Decreto $\mathrm{N}^{\mathrm{0}} 5.813$, de 22 de junho de 2006, estabelece diretrizes e linhas prioritárias para o desenvolvimento de ações pelos diversos parceiros em torno de objetivos comuns voltados à garantia do acesso seguro e uso racional de plantas medicinais e fitoterápicos em nosso país, ao desenvolvimento de tecnologias e inovações, assim como ao fortalecimento das cadeias e dos arranjos produtivos, ao uso sustentável da biodiversidade brasileira e ao desenvolvimento do Complexo Produtivo da Saúde ( BRASIL, 2006)
\end{abstract}

Para conceituar o que é política pública Secchi (2015) nos auxilia dizendo que, políticas públicas ou (public policy) tratam da orientação para a decisão e para a ação, tendo significado no conteúdo concreto e simbólico de decisões políticas, do processo de construção e atuações e resultados dessas decisões. Assim, a política pública transforma-se em uma diretriz para a resolução de um problema público.

Para contextualizar o significado e o conceito assim como o processo de trabalho inserido nas Pastorais da Saúde há a necessidade de conhecer o significado de saúde e como pode acontecer o binômio saúde/doença. Podemos utilizar concepções como da Organização Mundial da Saúde: saúde é o estado de completo bem estar físico, mental e social e não apenas a ausência de doença. Na VIII Conferência Nacional de Saúde de 1986 esse conceito foi ampliado afirmando que saúde é o resultado das condições de alimentação, moradia, educação, meio ambiente, trabalho e renda, transporte, lazer, liberdade e, principalmente, acesso aos serviços de saúde (COSTA, CARBONE, 2004).

Tal conferência como colocado acima faz referência aos fatores determinantes e condicionantes da saúde como: idade, sexo, hereditariedade (biológico), água, alimentação, moradia (físico- ambiente); ocupação, emprego, renda, crenças, valores (socioeconômico e cultural) e serviços de saúde. Utilizamos o texto de Starfield (2002) ao afirmar que a saúde individual ou coletiva tem em sua determinação aspectos genéticos, que podem ser físicos e sociais e fortemente modificados pelo ambiente (meio). Além dos aspectos sociais que o indivíduo está inserido, também modificado por comportamentos que são materializados culturalmente e ou socialmente e também pela qualidade dos serviços de saúde organizados e oferecidos. 
As dimensões da Pastoral da Saúde são descritas por Barchifontaine (2016), como: solidária (visita aos doentes nas instituições de saúde, famílias e comunidade), comunitária (educação e promoção à saúde através da produção de medicamentos fitoterápicos), política institucional (atuação junto a instituições públicas e privadas, assim como em instâncias de participação popular, Conselho de Saúde).

Percebe-se até aqui que o processo saúde e doença ao qual a Pastoral da Saúde está inserida possui muitas variáveis. Para cumprir então, a finalidade deste estudo foi utilizada metodologia quantitativa abordada por Moreira (2011); usando métodos referenciados por Gil (2007): a busca bibliográfica evidenciada pela construção teórica; a coleta de dados utilizando como instrumento observação participante e entrevista estruturada (questionário com perguntas fechadas aplicadas no mês de novembro de 2016 à população alvo após a apresentação e assinatura do termo de consentimento livre e esclarecido aos mesmos) e; análise dos dados coletados. Utilizado como população alvo os agentes das Pastorais da Saúde do município e os usuários destas.

Este estudo está organizado da seguinte forma: apresentação das pastorais atuantes no município; abordagem do significado de cultura na visão dos agentes da pastoral da saúde e dos usuários que utilizam os produtos ali produzidos; apresentação do conhecimento acerca das práticas e saberes da Pastoral da Saúde na visão dos usuários deste serviço e; significado do trabalho por parte dos agentes que ali atuam e dos usuários destes serviços; finalizando com discussão dos resultados e considerações.

\section{Apresentando as Pastorais da Saúde e os Agentes atuantes no município}

A Pastoral da Saúde da Paróquia São Francisco de Borja (pastoral do centro) está alocada nas dependências da Igreja Matriz, no centro da cidade, com início de suas atividades em 2004. O Trabalho é realizado durante os quatro dias da semana (segunda a quinta), com processo de trabalho que é executado seguindo as dimensões da pastoral: Solidária: visita aos enfermos com início em 2004;Comunitária: produção de medicamentos fitoterápicos, e disponibilização destes produtos para a comunidade local, início em 2008;Política institucional: Conselho Municipal de Saúde, onde conseguiram duas vagas para busca e participação nas discussões de saúde.

Quanto à participação no conselho municipal de Saúde esta é referenciada na lei 8.142 de 1990, que cria os Conselhos de Saúde, órgão deliberativo, fiscalizador com participação 
paritária, ou seja, representantes da comunidade e do governo em número igual. Importante local de planejamento, discussão e decisões frente à saúde pública municipal. E a Pastoral da Saúde se insere numa importante política pública de participação social e do SUS (Sistema Único de Saúde).

A Pastoral da Saúde da Paróquia Imaculada Conceição (Pastoral do Passo), está ligada e alocada junto a Igreja Matriz no Bairro do Passo. Composta por oito integrantes, todas mulheres, iniciou suas atividades em 1986, segundo informações de suas integrantes. O processo de trabalho acontece dentro de uma dimensão que é a comunitária, as outras duas não estão em atividade em função da falta de recursos humanos, ou seja, um número maior de agentes capacitados para tais dimensões. O processo de trabalho ocorre em dois dias da semana, terças e quintas à tarde, acontecendo neste momento a produção de medicamentos fitoterápicos e o atendimento aos usuários.

Possui recursos financeiros e materiais em menor disponibilidade para auxílio e melhoria estrutural e ambiental do trabalho realizado pelas agentes. A pastoral também possui independência financeira da Igreja. Também conta com um brechó realizado nas dependências desta, para aumento de recursos, possibilitando compra de produtos para confecções dos medicamentos fitoterápicos, os quais não possuem tabela de preço mas sim o recebimento do valor que o usuário puder dispor. Evidenciando assim a finalidade da pastoral que é a promoção, cuidado e defesa da integridade e da vida de quem deste serviço necessitar.

Nas duas Pastorais da Saúde estudadas há a presença do (a) agente da pastoral que trabalha na dimensão comunitária. Estes realizam o seu trabalho seguindo as dimensões que o processo de trabalho ou as ações respectivas devem seguir. Para aprofundar o conhecimento referente a quem é o agente da Pastoral da Saúde, Silva (2012) afirma que o agente é uma pessoa da comunidade, sob orientação de um Pároco, e que se coloca a serviço das pessoas ou comunidade colaborando com suas ações para o fortalecimento da saúde de todos. A presença do agente da pastoral no trabalho comunitário é importante não só pelas condições de doença do povo e má condição de qualidade de vida, mas como vocação cristã. É uma pessoa que possui e recebe preparação e conhecimento, que entende a missão da igreja diante do pluralismo religioso, que não discrimina nem julga, utilizando uma larga criatividade religiosa.

E esta prática se dá quando em observação foi possível perceber que no trabalho desenvolvido no preparo e distribuição dos remédios fitoterápicos, não são atendidos somente 
católicos, mas pessoas que vêm buscar auxílio e resolução da sua necessidade. Não há distinção de religião neste momento, mas um envolvimento profundo em atender as pessoas, promovendo bem estar, tranquilidade e um ambiente acolhedor. Na tentativa de chegar o mais perto possível da resolução do problema que estas pessoas naquele momento necessitam e que ali procuram auxílio.

Martins (2010) acrescenta que o agente da Pastoral da Saúde é aquele que atua nesta, pessoas motivadas pela "fé em Cristo", com disponibilidade para realizar o trabalho na pastoral e formação, que tenha responsabilidade, saiba trabalhar em equipe, sem preconceitos e comprometida coma defesa da vida. Pessoas independentes de sua opção religiosa mas que façam o bem ao próximo podem trabalhar na Pastoral da Saúde. Presente em todo o Brasil com grupos ligados a comunidade católica, atuam em uma variedade de locais relacionados à saúde, instâncias políticas, visitas aos enfermos tanto em instituições hospitalares como em domicílios.

É possível perceber que no texto de Martins há um perfil traçado para o agente da pastoral que evidenciam traços éticos e bioéticos, como o comprometimento com a vida. Trata-se de um trabalho voluntário, não remunerado, que requer comprometimento, sigilo, respeito, comportamentos e saberes que não prejudiquem e sim promovam a saúde e a dignidade de vida das pessoas beneficiadas com este trabalho. Melhorando a saúde tanto de pessoas que utilizam os produtos feitos na dimensão comunitária, como aqueles assistidos em visitas quando institucionalizados (hospitalização por motivo de doença) ou em seu domicílio. Além da participação popular através do Conselho de saúde ou em parceria com instituições.

Durante a construção da observação participante dentro das duas instituições foi possível entrar em contato com alguns destes agentes na pastoral do Centro e todas as agentes na pastoral do Bairro do Passo. No gráfico a seguir está alocado o perfil idade, pertinente aos agentes da pastoral, lembrando que os codinomes P1 a P9 são agentes da pastoral do Centro e P10 a P16 agentes da pastoral do Bairro do Passo: 


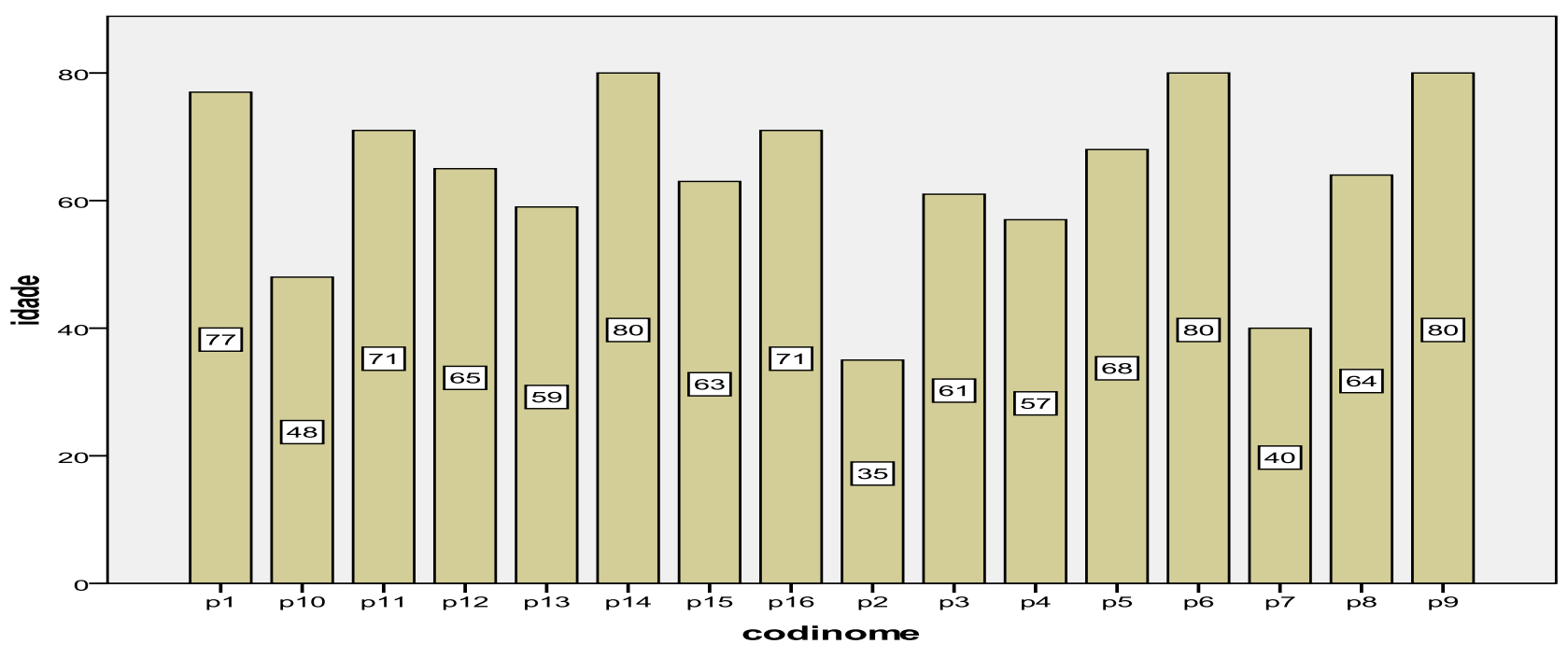

Gráfico 1-Idade dos Agentes da Pastoral da Saúde

Fonte: Pastoral da Saúde. Elaborado pelas autoras.

Analisando o gráfico acima, pode-se verificar que 11 dos 16 agentes entrevistados possuem idade acima de 60, destes: seis realizam atividades na pastoral do Centro e cinco na pastoral do Passo, os demais estão distribuídos entre idades de 35 anos a 59 anos. Partindo da amostra pesquisada o trabalho é realizado por pessoas de idade mais avançada, com maior vivência e experiência e acima de tudo pessoas ativas. Outra proposta para identificar o perfil dos agentes foi buscar conhecer qual a sua ocupação fora da Pastoral da Saúde:

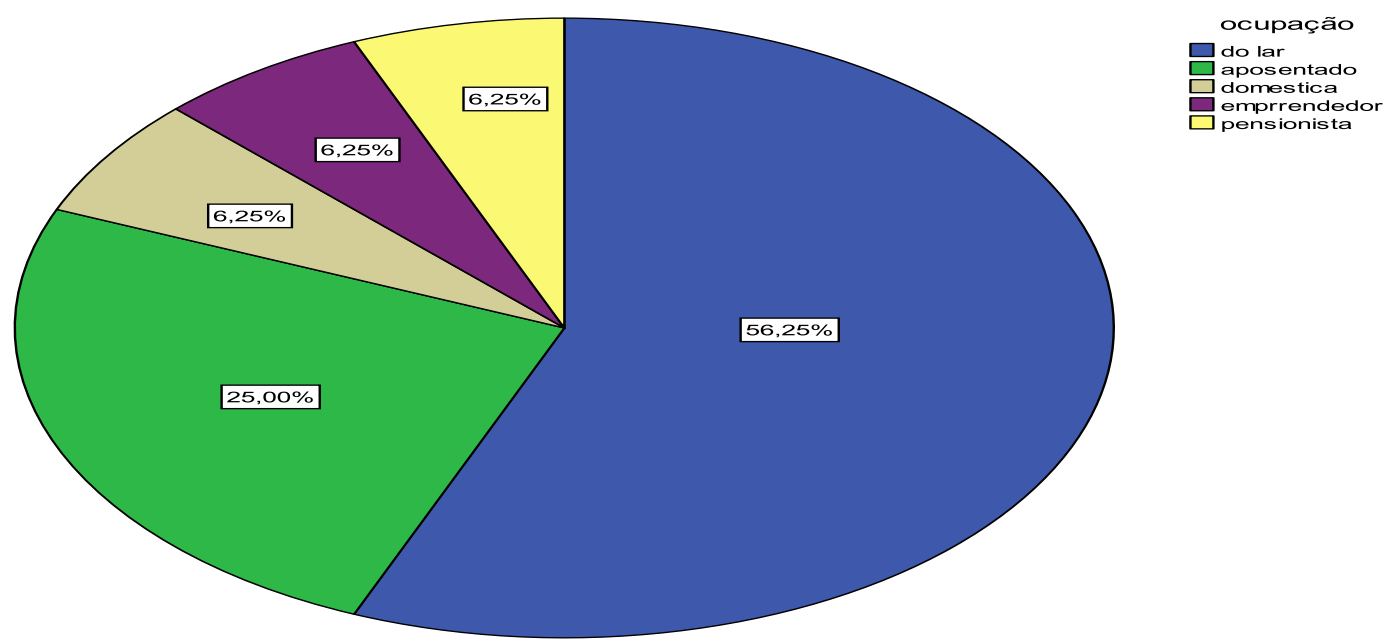

Gráfico 2 - Ocupação do Agente da Pastoral da Saúde

Fonte: Pastoral da Saúde. Elaborado pelas autoras 
Este gráfico demonstra que a maioria dos trabalhadores da Pastoral da Saúde que foram pesquisados tem como ocupação em primeiro lugar, ser do lar e em segundo, ser aposentado. Já a ocupação doméstico, empreendedor e pensionista ficam no mesmo nível de resultado ( $6,25 \%)$. Conclui-se que a maioria dos participantes não possui um emprego formal, podendo ser um aspecto favorável a disponibilidade de tempo para o trabalho voluntário. Foi considerado importante verificar os anos de trabalho realizado nas pastorais conforme o gráfico abaixo:

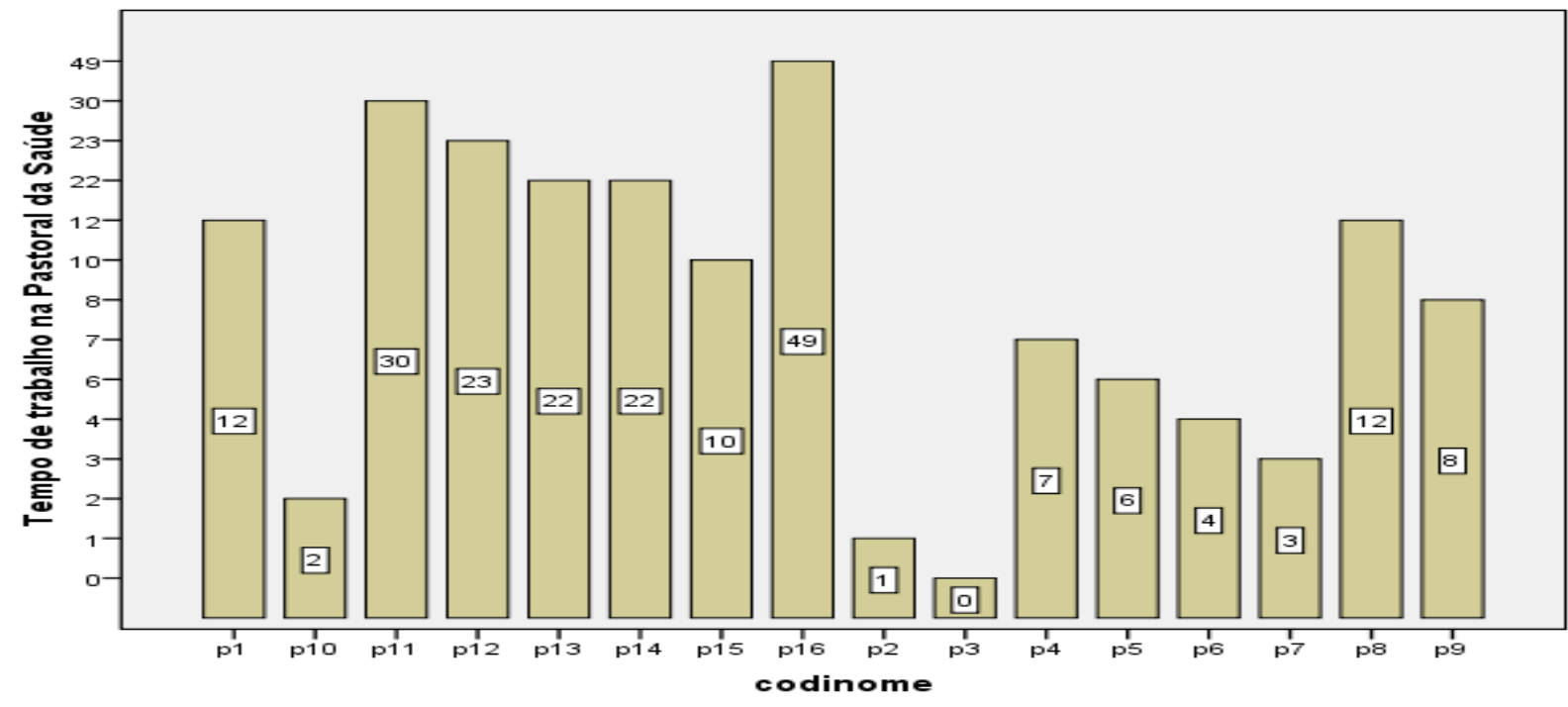

Gráfico 3 - Anos de trabalho Na Pastoral da Saúde

Fonte: Pastoral da Saúde. Elaborado pelas autoras.

Importante a análise deste gráfico fazendo uma relação de que a Pastoral do Passo existe desde o ano de 1986 (30 anos), conforme informação das agentes que ali trabalham. Então, ao observar no quadro a disposição os codinomes P10 a P16, o tempo fica entre 10 anos e 49 anos de trabalho voltado à Pastoral da Saúde com a maioria há mais de 20 anos, ou seja, o que caracteriza o trabalho contínuo, voluntário de cuidado e envolvimento com a qualidade de vida das pessoas que ali vem buscar os produtos além do domínio das práticas e saberes que ali são desenvolvidas.

É necessário direcionar o olhar para estes serviços, que se constituem em práticas importantes na inserção comunitária e no cuidado à saúde das pessoas inseridas nesta realidade. É importante a relação entre o trabalho da pastoral e as políticas públicas de saúde (SUS), e também políticas integrativas de práticas alternativas como a Política Nacional de 
plantas medicinais e fitoterápica, buscando incentivar a continuidade deste trabalho pastoral no auxilio da comunidade.

\section{Significado de cultura na visão dos agentes e dos usuários da Pastoral da Saúde}

A percepção dos agentes e dos usuários sobre o trabalho da pastoral é que este traduz uma cultura mostrado nos gráficos abaixo:

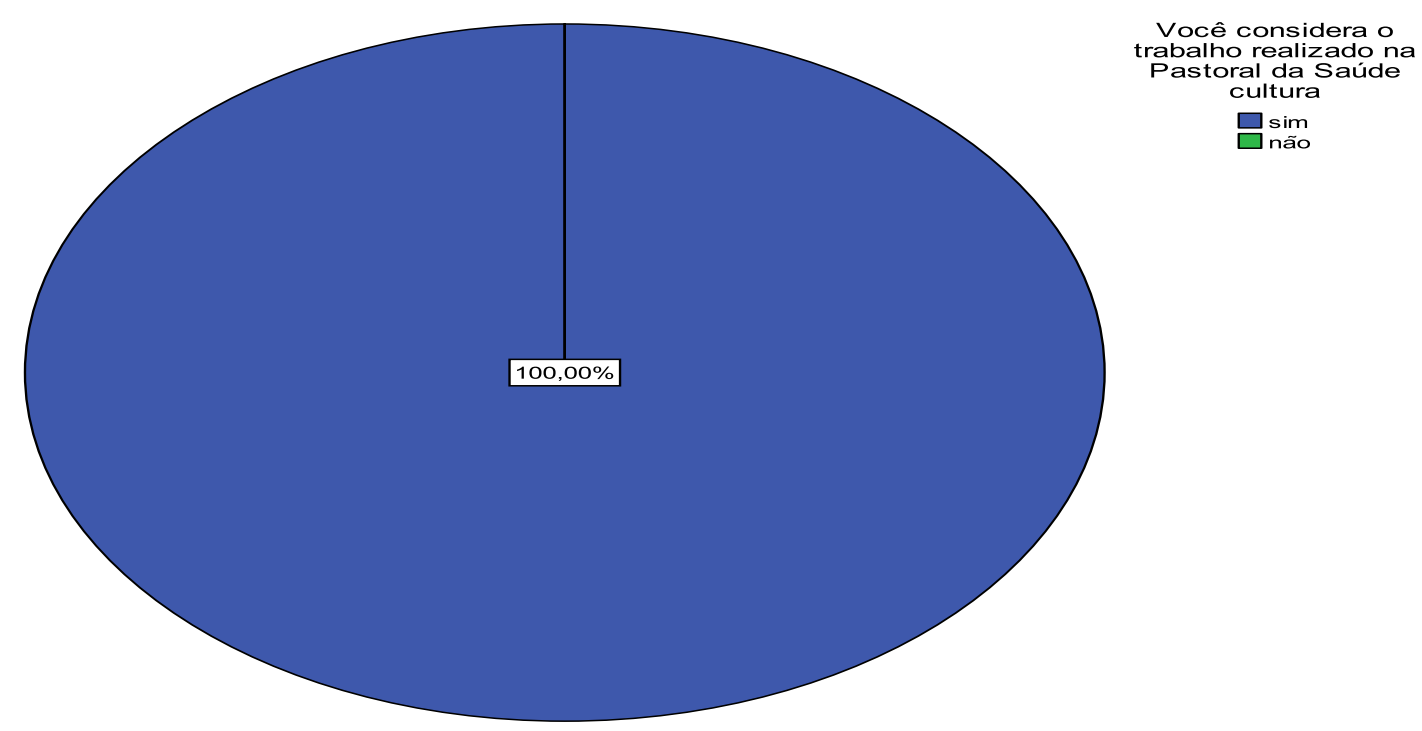

Gráfico 4 - Visão dos agentes e dos usuários quanto ao trabalho da Pastoral Saúde

Fonte: Pastoral da Saúde. Elaborado pelas autoras.

A partir destes resultados é importante aprofundar o conhecimento sobre o conceito de cultura ligado ao contexto do trabalho nas pastorais estudadas, nas práticas e saberes que ali acontecem. Eagleton (2011) aborda vários e relevantes conceitos e contextos de cultura, referindo que cultura tem como um dos primeiros significados: lavoura, cultivo, que também designava inicialmente o processo material e, posteriormente, é tomado como assuntos do espírito, refletindo uma transição da humanidade da existência rural para urbana, podendo então significar desde cultivo até prestar culto, proteção e cuidado.

Outro autor, Geertz (2008) relaciona cultura e nossa formação enquanto homens, dizendo que se tornar humano é buscar ser individual através dos padrões culturais, hábitos, crenças, comportamentos, significados que darão sentido e direção à vida. Partindo disso foi buscado identificar o significado de cultura para os investigados ( agentes e usuários), como disposto nos gráficos que seguem 


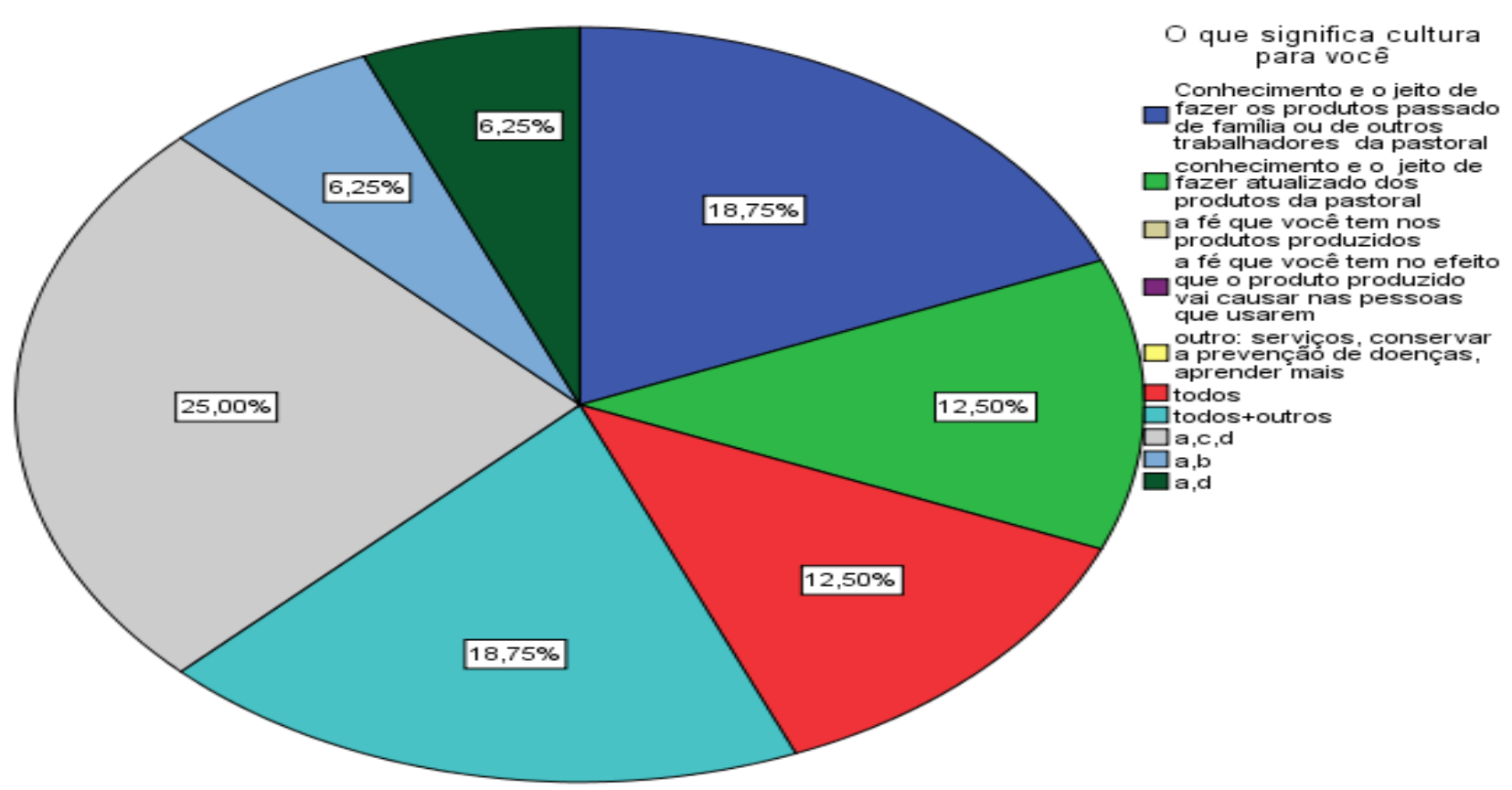

Gráfico 5 - Significado de cultura na visão do agente da pastoral

Fonte: Pastoral da Saúde. Elaborado pelas autoras.

Observação: Gráfico 5: a: Conhecimento e o jeito de fazer os produtos passado de família ou de outros trabalhadores da pastoral; b:conhecimento e o jeito de fazer atualizado dos produtos da pastoral; c: a fé que você tem nos produtos produzidos da pastoral; d: a fé que você tem no efeito que o produto vai causar na pessoas que usarem; e: outro: serviços, conservar a prevenção de doenças, aprender mais; f: todos; g: todos + outros; h: a,b,c; i: a,b; h: a,d.

$\mathrm{Na}$ visão dos agentes da pastoral o conhecimento e o jeito de fazer os produtos passado de família ou de outros trabalhadores da pastoral, a fé que você tem nos produtos produzidos da pastoral e a fé que você tem no efeito que o produto produzido vai causar nas pessoas que usarem, teve maior percentual de opção ficando com $25 \%$ cada. Este resultado evidencia que além do conhecimento repassado de família ou do meio em que se vive a fé no que se produz e no uso dos produtos é considerada como significado de cultura. 


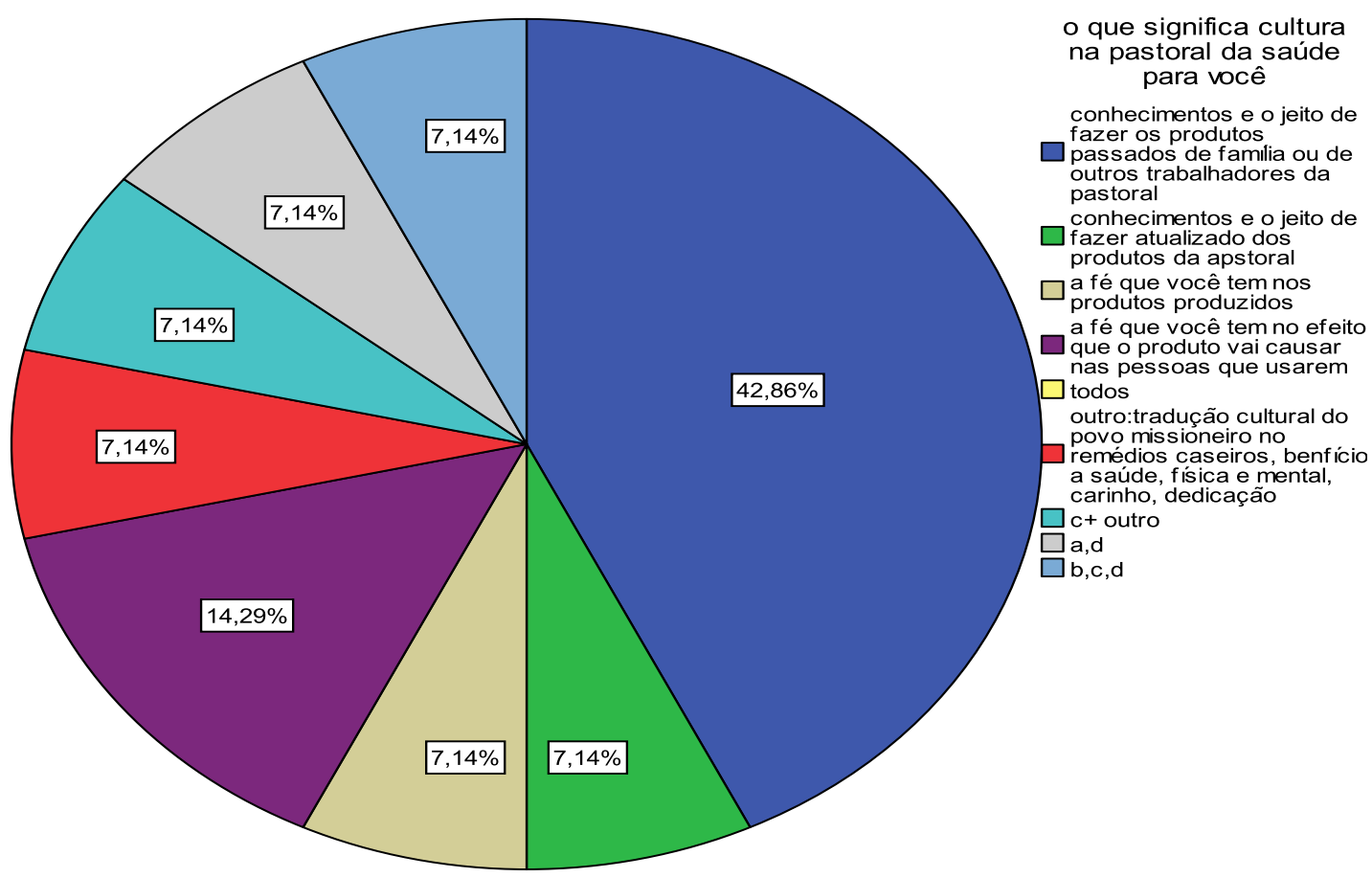

Gráfico 6 - Significado de cultura na visão do usuário da pastoral

Fonte: Pastoral da Saúde. Elaborado pelas autoras.

Observação: Gráfico 6: a: conhecimentos e o jeito de fazer os produtos passados de família ou de outros trabalhadores da pastoral; b: conhecimentos e o jeito de fazer atualizado dos produtos da apstoral; c: a fé que você tem nos produtos produzidos; d: a fé que você tem no efeito que o produto vai causar nas pessoas que usarem; e: outro:tradução cultural do povo missioneiro no remédios caseiros, benefício a saúde, física e mental, carinho, dedicação; f: todos;

A visão dos usuários sobre o significado de cultura dentro do trabalho da pastoral da saúde ficou em sua maioria $42,86 \%$ com o aspecto conhecimentos e o jeito de fazer os produtos passados de família ou de outros trabalhadores da pastoral, e em segundo lugar, a fé que você tem no efeito que o produto vai causar nas pessoas que usarem.

\section{Práticas e saberes da Pastoral de Saúde na visão de quem faz e de quem utiliza os produtos da Pastoral da Saúde}

Outra questão investigada foram as práticas e saberes do trabalho dos agentes na visão destes e dos usuários nos gráficos que seguem. 


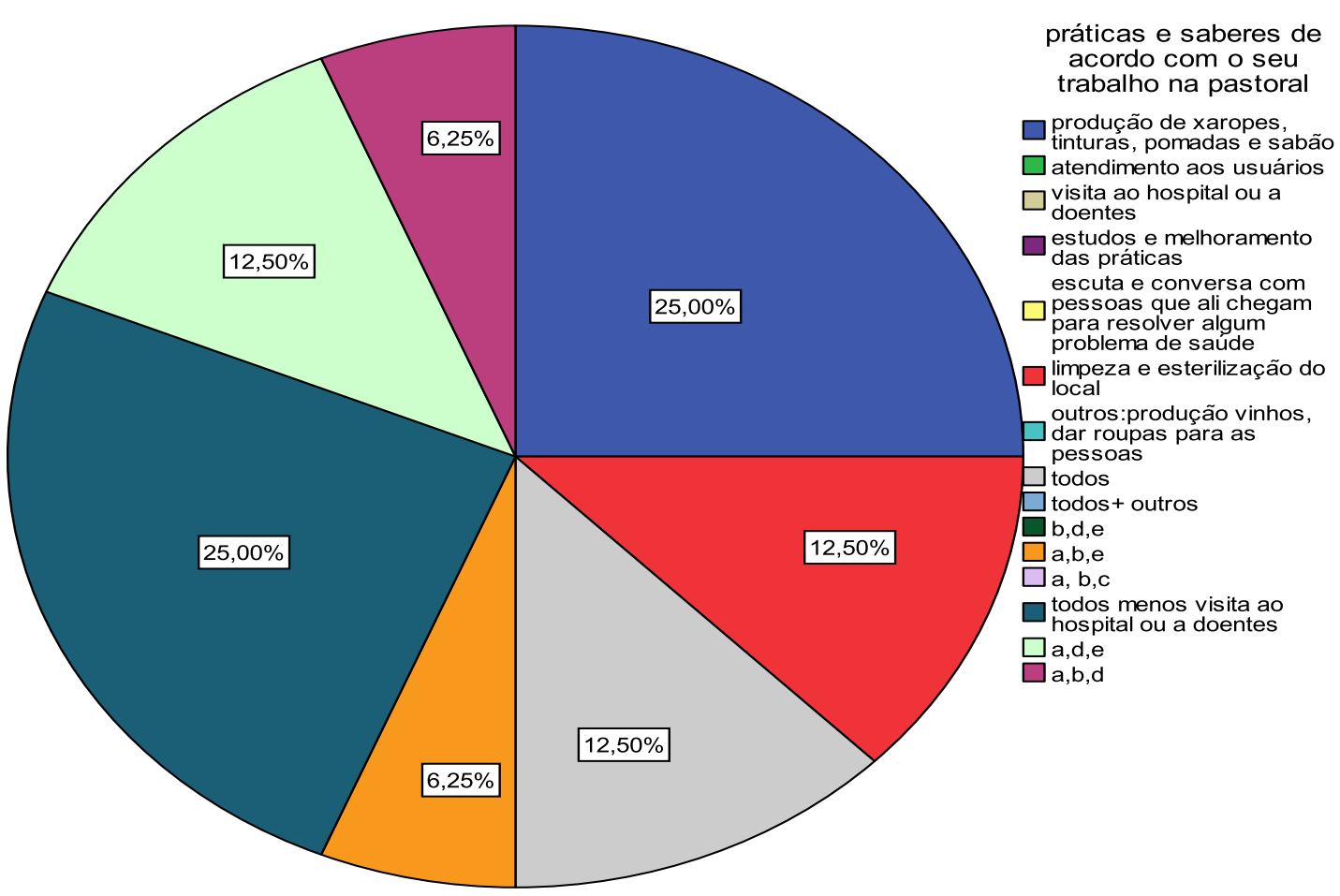

Gráfico 7- Práticas e saberes na visão do agente da pastoral

Fonte: Pastoral da Saúde. Elaborado pelas autoras.

Observação: Gráfico 7: a: produção de xaropes, tinturas, pomadas e sabão; b: atendimento aos usuários; c: visita ao hospital e ou doentes $\mathbf{d}$ : estudos e melhoramento das práticas; e: escuta e conversa com pessoas que ali chegam para resolver algum problema de saúde; f: limpeza e esterilização do local; g:outro: produção de vinho, dar roupas para as pessoas; h: todos; I: todos menos visita ao hospital.

Todas as alternativas de práticas e saberes foram apontadas como significativas pelos mesmos, pois cada uma recebeu $25 \%$, exceto a visita ao hospital. Isto sugere que os atuantes não a percebem como parte integrante da sua cultura, embora ela ocorra. 


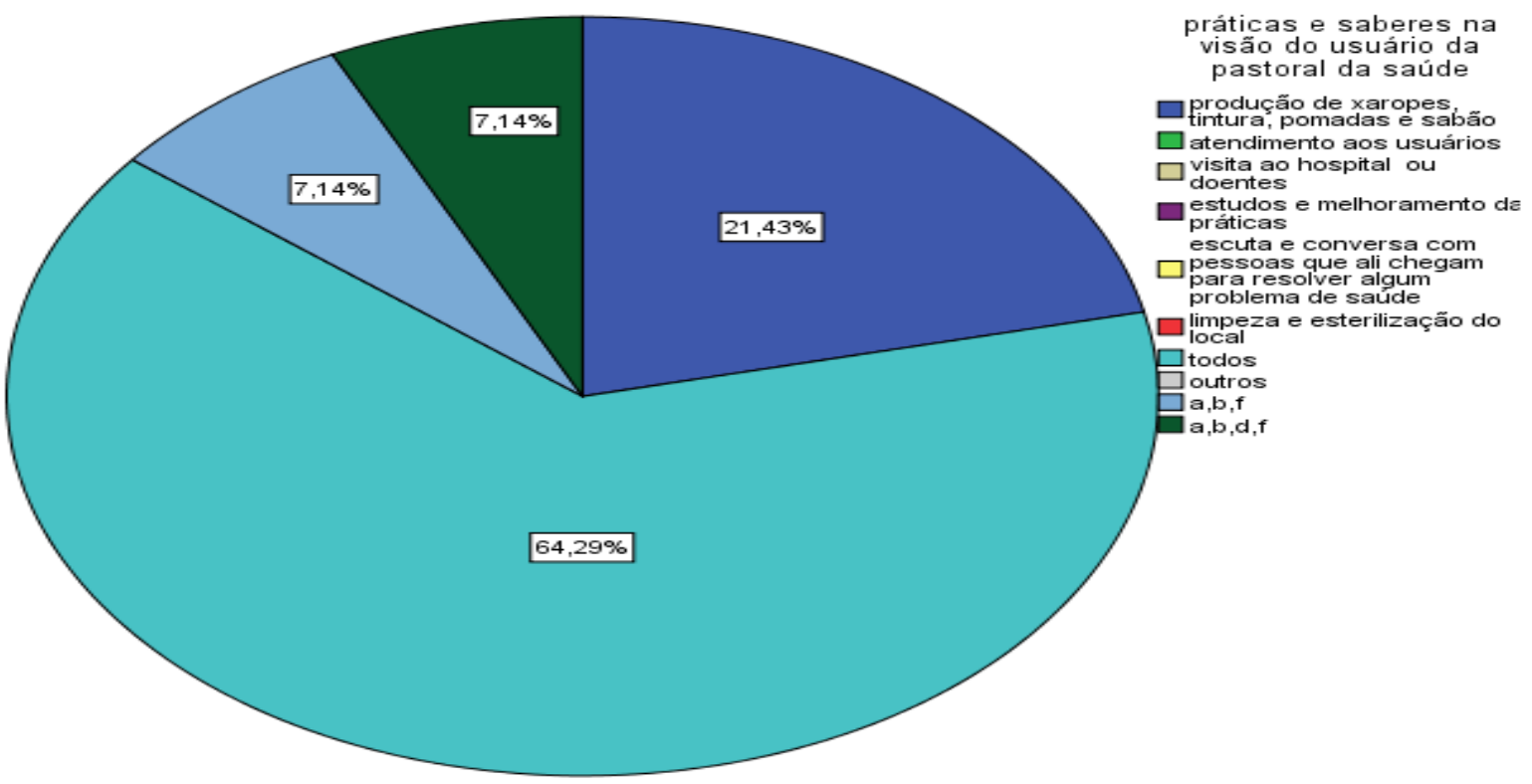

Gráfico 8 - práticas e saberes na visão do usuário da Pastoral

Fonte: Pastoral da Saúde. Elaborado pelas autoras.

Observação: Gráfico 8: a: produção de xaropes, tinturas, pomadas e sabão; b: atendimento aos usuários; c: visita ao hospital e ou doentes $\mathbf{d}$ : estudos e melhoramento das práticas; e: escuta e conversa com pessoas que ali chegam para resolver algum problema de saúde; f: limpeza e esterilização do local; g:todos .

$\mathrm{Na}$ visão dos usuários pode-se verificar que a alternativa, "todos" teve $64,23 \%$ de resultado, ficando em segundo lugar a produção de xaropes, tinturas, pomadas e sabão com 21,43\%. Isto evidencia que as ações comunitárias coma a produção de remédios fitoterápicos ou caseiros e o atendimento aos usuários, principalmente através da escuta e conversa, são constitutivos na definição das práticas e saberes pelos usuários. Sobretudo durante os momentos de visitas nos quais mostram a necessidade que algumas pessoas têm de serem ouvidas, tornando-se por vezes um ambiente de apoio psicológico. Em muitos momentos há emoções (lágrimas), situações em que a escuta tem o papel de amenizar o problema.

\section{Significado do trabalho na pastoral da saúde}

Analisando os gráficos abaixo é possível verificar a visão do agente e dos usuários em relação ao significado do trabalho na pastoral: 


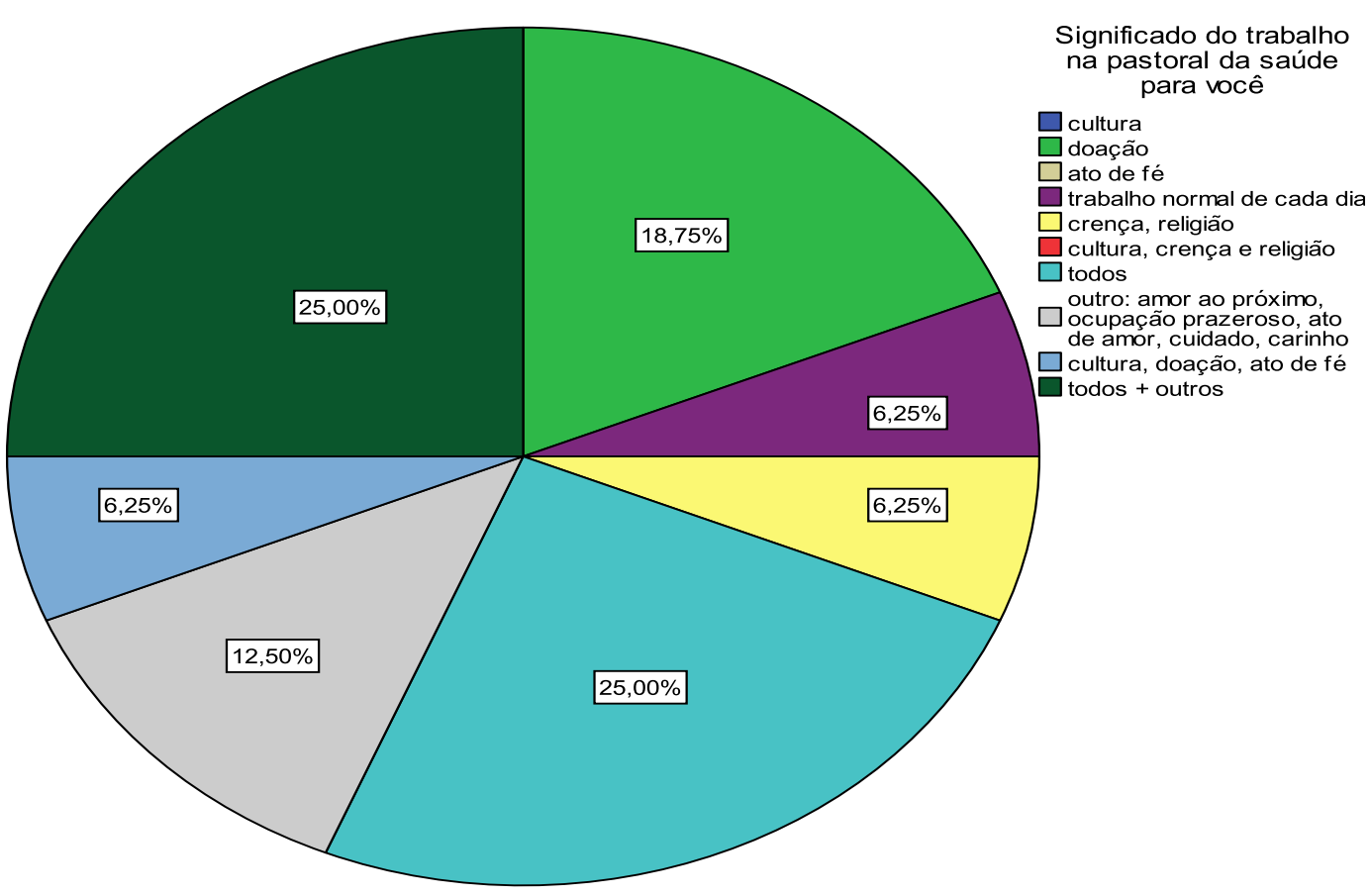

Gráfico 9 - Significado do trabalho na pastoral na visão do agente

Fonte: Pastoral da Saúde. Elaborado pelas autoras.

Ao serem questionados sobre o significado do trabalho os agentes apontam da mesma forma todas as opções oferecidas, cujo elemento comum é a doação ou amor ao próximo. Complementando o texto acima Silva (2012) afirma que o agente da Pastoral da saúde deve ter paciência, acolher e ouvir, respeitar valores de todos inclusive de religiões diferentes da sua, respeitar a religiosidade popular e ter humildade com aqueles que assiste. No gráfico abaixo podemos verificar a visão do usuário: 


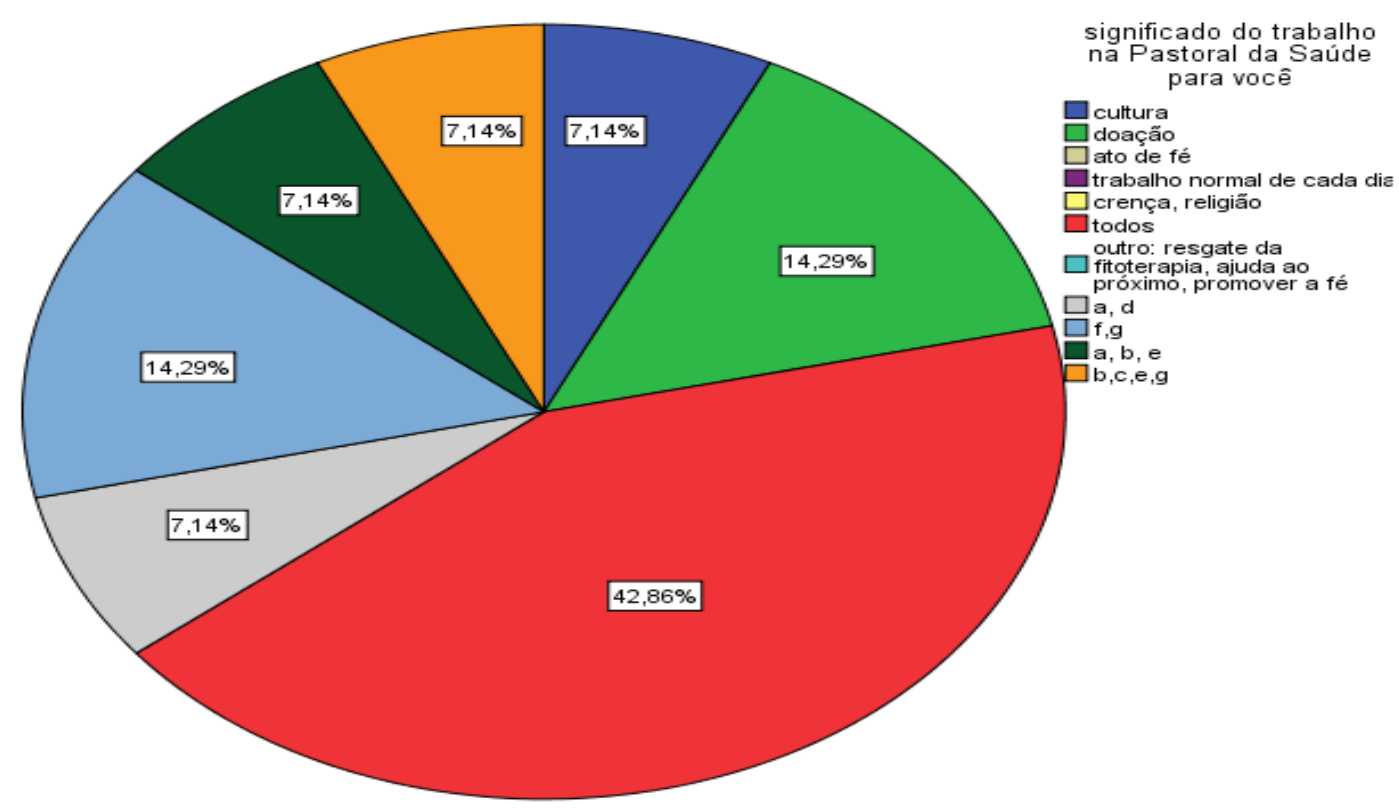

Gráfico 10 - Significado do trabalho na pastoral na visão do usuário

Fonte: Pastoral da Saúde. Elaborado pelas autoras.

Observação:Gráfico 10 : a : cultura; b: doação; c: ato de fé; d: trabalho normal de cada dia; e: crença, religião; f:todos; g: outros ( resgate da fitoterapia, ajuda ao próximo, promover a fé).

Os usuários apontaram como significado, em primeiro lugar a opção "todos" com 42,66\% e em segundo lugar empatados as opções: doação e outros (resgate da fitoterapia, ajuda ao próximo, promover a fé) com 14,29\% cada. Em relação a estes resultados é possível utilizar a afirmação de Durães e Sousa (2011), que a Pastoral da Saúde significa mais do que cidadania, o cuidado integral da pessoa, este refletido física, mental, social e espiritual. O que é identificado também por Barchifontane, (2016) que afirma: a pastoral é solidariedade em ação que perpassa territórios pessoais e familiares, tem sua ação na comunidade - comunitária. Evidenciando a luta pelos direitos fundamentais da saúde, integral e integrada, sendo sua tarefa o zelo pela vida através do cuidado, promovendo e celebrando-a.

\section{Dos resultados}

Observamos que o trabalho desenvolvido nas pastorais estudadas pode ser inserido como patrimônio imaterial, que acontece através dos valores, crenças, e conhecimentos perpassados e atualizados de geração em geração, o que se consolida também pelo tempo de vida destas pastorais, ou seja, entre 12 e 30 anos; e pelo tempo de trabalho dos agentes em cada uma de 
suas pastorais. Em relação ao significado de cultura na visão do agente e ou usuário da pastoral o que mais teve evidencia foi a questão dos conhecimentos e o jeito de fazer os produtos passados de família ou de outros trabalhadores da pastoral, a fé que você tem nos produtos e a fé que você tem no efeito que este vai causar nas pessoas que usarem.

Dando continuidade ao texto acima e relacionado às práticas e saberes investigadas de acordo com o trabalho do agente na pastoral e do conhecimento do usuário vimos que tais aspectos foram elencados desde o prático como a preparação de xaropes, pomadas, assim como a escuta, e atendimento aos usuários, resultando num ambiente acolhedor, de espiritualidade, ajuda mútua, momento de inter-relação pessoal.

Quanto ao significado do trabalho na pastoral na visão do agente e do usuários respectivamente a doação e outros aspectos são evidenciados como ato de fé, amor ao próximo, cultura, crença e religião. Intensificando a visão de que estes significados estão mais ligados à cultura inserida no meio em que estas pessoas vivem resultado de hábitos, escolhas e valores que definem a dinâmica de suas vidas, assim como as dimensões que a pastoral deve desenvolver e o perfil do agente da pastoral, já referenciado anteriormente.

\section{Considerações finais}

O trabalho da Pastoral da saúde na dimensão comunitária se constitui no trabalho com e para pessoas, inseridas em um meio muitas vezes precário de saúde, ou de condições socioeconômicas, então surge como uma complementaridade ao sistema de saúde que hoje apesar de ser universal e integral, não consegue ser resolutivo. Importante a continuidade deste trabalho com a abordagem das dimensões sociais e político- institucionais que a Pastoral da Saúde está inserida e deve desenvolver em suas ações. Ao realizar a observação participante algumas condições como a melhoria dos recursos estruturais e humanos na Pastoral da Saúde do Bairro Passo passaram a ser foco de um planejamento. Através da construção de uma Matriz FOFA em conjunto com outras áreas do conhecimento, pessoas da comunidade, as agentes que ali trabalham e o Pároco desta pastoral, para que através de um trabalho conjunto possa ser reestruturada. Proporcionando assim, a continuidade deste trabalho, desta cultura, destas práticas e saberes constituindo a possibilidade de um novo estudo. 


\section{Referências}

BARCHIFONTAINE, C. O papel da Pastoral da Saúde na Igreja. Vida Pastoral. 2016, Disponível em <http://www.vidapastoral.com.br/wpcontent/uploads/2016/06/WEB_VP_310_final.pdf> acesso em novembro de 2016.

BRASIL. Constituição Federal 1988. 5 de outubro de 1988. Disponível em < http://www.planalto.gov.br/ccivil_03/Constituicao/Constituicao.htm $>$ acesso em 18 de julho de 2016.

BRASIL. Decreto 5.813, 22 de junho de 2006. Dispõe sobre a Política Nacional de Plantas Medicinais e fitoterápicas. Diário Oficial [da] República Federativa do Brasil. Brasília, DF, 23 de junho de 2006. Disponível em < 13http://www.mda.gov.br/sitemda/sites/sitemda/files/user_arquivos_64/Pol\%C3\%ADtica_Na cional_de_Plantas_Medicinais_e_Fitoter\%C3\%A1picos.pdf> acesso em novembro de 2016.

BRASIL. Lei 8080, outubro 1990. 19 de setembro de 1990. Lei Orgânica da Saúde. Diário Oficial [da] República Federativa do Brasil. Brasília, DF, 20 set, 1990. Disponível em < http://www.planalto.gov.br/ccivil_03/Leis/L8080.htm> acesso em 18 de julho de 2016.

BRASIL. Lei 8142, 28 de dezembro de 1990. Dispõe sobre a participação da comunidade na gestão do SUS. Diário Oficial 「da] República Federativa do Brasil Brasília, DF, 31 dez, 1990. Disponível em < http://www.planalto.gov.br/ccivil_03/leis/L8142.htm > acesso em 27 de julho de 2016.

COSTA, E. CARBONE, M. Saúde da Família: uma abordagem interdisciplinar. 1 ed. Rubio. Rio de Janeiro, 2004.

DURÃES, J. SOUZA, W. a pastoral da saúde e o sus: para que todos tenham vida em abundância. In: Segundo Congrsso de Humanização. Curitiba, 2011. Anais: PUC. Disponível em < http://anais.congressodehumanizacao.com.br/files/2012/07/RESUMO021.pdf $>$ acesso em novembro de 2016.

EAGLETON, Terry. A ideia de cultura. 2 ed. São Paulo: Unesp, 2011

GEERTZ, Clifford. A interpretação das Culturas. Rio de Janeiro: LTC, 2008 (cap. 2: O impacto do conceito de cultura sobre o conceito de homem).

GIL, A.C. Métodos e Técnicas de Pesquisa Social. 5 ed. Atlas. São Paulo, 2007.

LEANDRO, B. BAHIA, L. A agenda da CNBB para a Saúde: Uma análise da pauta dos documentos oficiais da entidade de 1952 a 2012. In: $2^{\circ}$ CONGRESSO BRASILEIRO DE POLÍTICA, PLANEJAMENTO E GESTÃO EM SAÚDE. Belo Horizonte, 2013. Anais: Universidade Federal do Rio de janeiro. Disponível em < http://www.politicaemsaude.com.br/anais/trabalhos/publicacoes/001.pdf $>$ acesso em outubro de 2016.

MARTINS, A. A Pastoral da Saúde e sua importância no mundo da saúde: da presença solidária ao transcender a dor e o sofrimento. O Mundo da Saúde. São Paulo, 2010.

Disponível em < http://www.saocamilo-

sp.br/pdf/mundo saude/79/18 A\%20Pastoral\%20da\%20Saude.pdf> acesso em outubro de 2016. 
MOREIRA. M. Metodologia de pesquisa em ensino. LF Editorial. São Paulo. 2011.

OLIVEIRA, I. SOUZA, W. A Pastoral da Saúde da arquidiocese de Curitiba e seus desafios. In: Jornada Interdisciplinar de Pesquisa em Teologia e Humanidades. Curitiba, 2011. Anais PUC- Escola de Educação e Humanidades. Disponível em < https://www.google.com.br/search?q=Pastoral+da+Sa\%C3\%BAde+da+arquidiocese+de+Curi tiba+e+seus+desafios\&oq=Pastoral $+\mathrm{da}+\mathrm{Sa} \% \mathrm{C} 3 \% \mathrm{BAde}+\mathrm{da}+$ arquidiocese + de+Curitiba+e+se $\underline{\text { us }+ \text { desafios \&aqs }=\text { chrome..69i57.2041j0j7\&sourceid }=\text { chrome } \& i e=U T F-8>}$ acesso em novembro de 2016.

SECCHI, L. Política Públicas: Conceitos, esquemas de análise, casos práticos. 2 ed. Cengage Learning, São Paulo, 2015.

SILVA, A. PERFIL DO AGENTE DE PASTORAL DA SAÚDE. ISCAL, novembro de 2012. Disponível em <

http://www.iscal.com.br/iscal/upload/curso_capelania/perfil_do_agente_da_pastoral_da_saud e_e_agente_da_pastoral_da_saude.pdf> acesso em outubro de 2016.

STARFIELD, B. Atenção primária: equilíbrio entre necessidades de saúde, serviços e tecnologias. UNESCO, 2002.

TURINO, F. BELO, M. SILVA, A. Uma Visão Diagnóstica da Fitoterapia na Pastoral da Saúde. Natureza On Line , 2004 . Disponível em < http://www.naturezaonline.com.br/natureza/conteudo/pdf/Revista_Online_Fabiana\&Mary\&A ry.pdf> acesso em outubro de 2016. 